\title{
Programa Fome Zero do Presidente Lula e as perspectivas da Renda Básica de Cidadania no Brasil'
}

\section{President Lula's Fome Zero Program and prospects for basic citizenship income in Brazil}

\author{
Eduardo Matarazzo Suplicy \\ Senador (PT-Partido dos Trabalhadores / Estado de São Paulo), \\ Professor de Economia na Escola de Administração de Empresas \\ de São Paulo, da Fundação Getúlio Vargas, Ph.D. em Economia \\ pela Michigan State University (USA). \\ E-mail: esuplicyळsenado.gov.br
}

\section{Resumo}

$\mathrm{O}$ artigo discute o contexto em que se inicia o Programa Fome Zero do Presidente Lula, no Brasil. Parte de dados da distribuição de renda no Brasil, faz uma descrição do Programa Fome Zero e seus diferentes subprogramas, passando a discutir os programas de transferência de renda implantados no país, desde 1995, ainda no governo de Fernando Henrique Cardoso. Após fazer uma síntese de cada um dos programas implantados, defende a adoção de uma Renda Básica de Cidadania distribuída a todos habitantes do país. Suas vantagens seriam: diminuição da burocracia, melhor atendimento às famílias pobres, eliminação de estigmas ou vergonha dos beneficiários, custo menor da distribuição, garantia de liberdade, dignidade e segurança alimentar a todos cidadãos. Termina por mostrar vantagens econômicas de tal renda para o desenvolvimento socioeconômico, ilustrando com exemplos do Alasca e do Mun. de São Paulo.

Palavras chave: Fome, Garantia de Renda Mínima, Transferência de Renda 


\section{Abstract}

The article discusses the socioeconomic background for the Fome Zero Program, then describes the Program and its subprograms, finally discusses programs of income transfer implemented in Brazil since 1995, during Fernando Henrique Cardoso administration. After doing an abstract of each program, explains the proposition of a Basic Income Guarantee and argues that it would present advantages for the country as a whole, illustrating with examples of the state of Alaska and of the municipality of Sao Paulo.

Key words: Hunger, Basic Income Guarantee, Income transfer
O Brasil está iniciando uma fase extraordinária na história da nação com a eleição do Presidente Luiz Inácio Lula da Silva, do Partido dos Trabalhadores, em Outubro de 2002, quando ele recebeu 53 milhões de votos ou $62 \%$ dos votos válidos dos brasileiros. Entre os principais objetivos do Presidente Lula estão a erradicação da fome e da pobreza absoluta, a promoção do crescimento econômico acompanhado por uma melhor distribuição de renda, a criação de empregos e a garantia de vaga na escola para cada criança.

Hoje o Brasil tem 175 milhões de habitantes, um Produto Interno Bruto (PIB) per capita (medida em PPP - Paridade do Poder de Compra) de US\$ 7.625 por ano e um Índice de Desenvolvimento Humano (IDH) de o,757 em 2000 (Relatório sobre Desenvolvimento Humano de 2002 das Nações Unidas) que está abaixo do esperado em relação ao nível de renda per capita. A razão disso está na alta taxa de desigualdade, como indicada pelo coeficiente de Gini de 6o,7 (1998), apenas abaixo dos apresentados pela Serra Leoa, 62,9 (1989), Suazilândia, 60,9 (1994) e República da África Central, 61,3 (1993)².

Existem hoje no Brasil grandes expectativas em relação às políticas que serão implementadas pelo Presidente Lula para atingir os principais objetivos mencionados acima. Foi neste contexto que ele anunciou o Programa Fome Zero para garantir que durante o seu governo cada brasileiro terá o direito a ter três refeições por dia.

Inicialmente, apresentarei a síntese do Programa Fome Zero de acordo com a apresentação oficial do governo federal e a seguir apresentarei os vários programas de transferência de renda que existem hoje no Brasil, além de uma análise de por que devemos racionalizar gradualmente todos eles e implementar uma renda básica de cidadania³.

\section{O Programa Fome Zero}

De acordo com José Graziano da Silva, principal coordenador deste programa e Ministro Extraordinário da Segurança Alimentar e Combate à Fome (MESA), o Programa Fome Zero tem como objetivo fornecer

22002 World Development Indicators.

3 MINISTÉRIO DE ESTADO EXTRAORDINÁRIO DE SEGURANÇA ALIMENTAR E COMBATE A FOME. Programa Fome Zero. Documento preliminar para discussão interno no CONSEA. Brasília, Versão 30/01/2003. 
quantidade, qualidade e regularidade de alimentos a todos os brasileiros. Isto significa fornecer segurança alimentar àqueles 46 milhões de habitantes que recebem menos de US\$1,oo por dia para sobreviver.

Simultaneamente, serão tomadas ações para promover produção e distribuição de alimentos de qualidade em base sustentável, além de promover a inclusão social, educação alimentar e nutricional. Isso será essencial para estimular práticas saudáveis de alimentação.

Graziano enfatiza que o programa está sendo criado para combater a fome e as causas da exclusão. 0 programa tem como objetivo expandir vários dos programas existentes. É um programa transversal que pretende estabelecer uma nova articulação com a esfera produtiva, estimulando a agricultura e a economia locais.

As primeiras medidas foram anunciadas no último dia 30 de janeiro com a instalação do Conselho Nacional de Segurança Alimentar e Nutricional (CONSEA), junto com a experiência que foi iniciada em fevereiro nos municípios do Estado mais pobre do Brasil, Piauí, que apresenta o menor Índice de Desenvolvimento Humano: Guaribas e Acauã, ambos localizados na região semi-árida, com uma população em torno de 5.000 habitantes.

Haverá uma implementação gradual das medidas. Uma delas é o cartão-alimentação, que proporcionará R\$ 50,oo (aproximadamente US\$ 15,00 ) por mês as famílias que receberem menos de $1 / 2$ salário mínimo per capita e outras limitações sociais e foram escolhidas naqueles municípios por um Comitê Gestor, no qual estão presentes membros da comunidade.

O governo não pretende fazer dos beneficiários dependentes do Programa Fome Zero. O programa está sendo criado para ajudar a população a superar a sua situação de exclusão. 0 maior de todos os benefícios que o Programa Fome Zero possa trazer, de acordo com Graziano, é ajudar na organização da sociedade. A organização é essencial para superar a pobreza.

Ações a serem desenvolvidas em 2003:

1. A formulação da Política Nacional de Segurança Alimentar pelo CONSEA.

2. Um conjunto de políticas públicas para garantir a segurança alimentar implementadas por MESA - Ministério Extraordinário da Segurança Alimentar e
Combate à Fome - interagindo com outros departamentos estatais, secretarias e governos municipais.

3. Um Mutirão contra a fome e a pobreza absoluta com o envolvimento total da sociedade brasileira.

4. Formulação da Política da Segurança Alimentar através do CONSEA, com avaliação contínua do Programa e a preparação da II Conferência sobre Segurança Alimentar no primeiro trimestre de 2004.

\section{Programa Nacional de Bancos de Alimentos}

Incentivo e ações de apoio àqueles que querem doar alimentos nos municípios de médio e de grande porte.

\section{Programas de Restaurantes Populares}

O objetivo é proporcionar refeições balanceadas a preços acessíveis aos trabalhadores.

\section{Cartão-alimentação}

O Programa de Cartão-Alimentação proporcionará às famílias de baixa renda um benefício de R\$ 50,oo para serem gastos em alimentos básicos na localidade onde moram essas famílias. Começando pela região semiárida, o programa associará esse benefício com políticas para promover a sua emancipação sócio-econômica, como:

- Educação nutricional e alimentar;

- Saúde e nutrição;

- Geração de emprego e renda;

- Abastecimento de água;

- Saneamento básico;

- Qualidade na reforma da construção ou moradia.

\section{Programa de Educação Nutricional e Alimentar}

Para disseminar práticas de boa nutrição, melhorando os hábitos de consumo e mostrando os valores dos alimentos locais, usando rádio, TV e todos os meios de comunicação.

Expansão deste programa com a colaboração do Ministério de Educação.

Aumentar o valor da merenda ou almoço por criança, estimulando:

- Fornecimento local, estimulando a produção local;

- Aumentando o valor nutricional do alimento;

- Treinamento das pessoas responsáveis pela preparação do almoço ou da merenda. 
Programa de Distribuição de Cestas Básicas Emergenciais

Para famílias que estão numa situação de risco alimentar e que preferem receber cestas básicas em vez do cartão-alimentação, tais como:

- 8o.ooo famílias encampadas aguardando assentamento no Programa de Reforma Agrária;

- Comunidades indígenas, aproximadamente 43.000 famílias;

- Comunidades de quilombos, aproximadamente 5.0oo famílias.

\section{Movimento Contra a Fome}

Todos os tipos de ações para promover doação de alimentos ou em dinheiro, preparação de cartilhas e panfletos de instruções, voluntários etc.

\section{Doações para Campanhas de Alimentos}

Podem ser feitas em:

- Em larga escala, para Conab (Companhia Nacional de Abastecimento);

-Em pequena escala, a serem organizadas pelos municípios.

\section{Doação em dinheiro}

Haverá contas bancárias oficiais para este objetivo (Contas Fome Zero no Banco do Brasil e na Caixa Econômica Federal).

\section{Cartilhas}

Para informar a população sobre os objetivos do programa.

\section{Campanha de Contribuição Voluntária}

Para estimular a participação de todos em cada município, ajudando a coletar e a distribuir todas as doações com o apoio do governo municipal, sindicatos, igrejas e famílias.

\section{Políticas Regionais Prioritárias}

\section{Políticas Estruturais Importantes que incluem:}

\section{Reforma Agrária}

- Preparação do Plano de Reforma Nacional;

- Plano urgente para assentar aquelas 8o.ooo famílias que estão esperando e morando em barracas
- Reestruturação dos assentamentos em situação precária.

\section{Fortalecimento da Agricultura Familiar.}

- Expansão do crédito rural (Pronaf - Programa Nacional de Fortalecimento da Agricultura Familiar);

- Financiamento da agricultura familiar durante a entressafra.

\section{Projeto de Emergência para Viver Bem na Área Semi-Árida}

- Implementação do Seguro de Colheita;

- Abastecimento Emergencial de Água;

- Construção de pequenas usinas hídricas, cisternas e açudes.

\section{Programa para Superar Analfabetismo}

- Programas para ensinar adultos beneficiados pelo Programa Fome Zero a ler e a escrever;

- Programas educacionais para jovens e adultos nas Regiões da Reforma Agrária.

\section{Programas para Geração de Emprego}

- Financiamento de moradia e saneamento para famílias de baixa renda;

- Expansão do financiamento de microcrédito;

- Incentivo ao turismo rural

\section{Programa de Combate à Desnutrição Materno-In- fantil}

- Programa de Bolsa Alimentação - Programa de Renda Mínima vinculada à Saúde;

- Atenção à saúde básica.

Para o ano de 2003, o Orçamento Federal Anual alocou R\$ 1,.8 bilhão para o Programa Fome Zero. Em meados de fevereiro o governo anunciou um corte geral de despesas para todos os ministérios, incluindo MESA. Entretanto, nesse caso, um corte de apenas R\$ 30 milhões sobre R\$ 1,8 bilhão, era proporcionalmente pequeno comparado com outras áreas. Os outros ministérios também poderão incluir os seus próprios recursos para expandir as ações coordenadas do Programa Fome Zero. 


\section{Os Programas de Transferência de Renda}

É importante saber que o Programa Fome Zero está sendo lançado numa época em que o Presidente Lula está anunciando que iniciará a Reforma da Previdência, a Reforma Tributária e a Reforma da Legislação Trabalhista. É importante também saber que uma evolução significativa ocorreu nos anos recentes em relação aos programas de transferência de renda para reduzir a pobreza, e isso deve ser levado em consideração ${ }^{4}$.

Uma transformação relevante foi a decisão de substituir a distribuição de cestas básicas para famílias pobres, que apresentou um aumento de aproximadamente 3 milhões em 1995 para 30 milhões em 1998, com programas de transferência de renda que foram ampliados desde então. No final da administração do governo Fernando Henrique Cardoso, em 2002, tivemos os seguintes programas em vigor:

Programa de Agente Jovem, instituído em 2001, para jovens de 15 a 17 anos, em situação de risco social nas famílias com renda abaixo de meio salário mínimo per capita, com o direito a receber R\$ 65,00 por mês. Havia 105 mil cadastrados neste programa controlado pelo Ministério da Previdência e Assistência Social em outubro de 2002. A partir de 2003, este ministério foi desmembrado em dois, e o programa passa a ser de responsabilidade do Ministério de Assistência e Promoção Social.

Programa para Erradicação do Trabalho Infantil (PETI), criado em 1996, para famílias que tem crianças de 7 a 14 anos trabalhando em atividades pesadas ou de risco, que recebem menos de meio salário mínimo per capita, com o direito a receber R\$ 25,0o por mês nas áreas rurais ou R\$ 40,oo por mês nas áreas urbanas. Havia 810 mil beneficiários cadastrados em outubro de 2002. Este programa também era de responsabilidade do Ministério da Previdência e Assistência Social Assim, a partir de 2003, passa a ser de responsabilidade do Ministério de Assistência e Promoção Social. 0 orçamento anual deste programa em 2003 é de R\$ 503 milhões.
Bolsa Escola ou Programa de Renda Mínima vinculada à Educação, criada inicialmente em 1997, através da Lei 9.533/97 e ampliada em 2001, com a Lei 10.219/o1, que fornece às famílias com crianças de 6 a 15 anos, com renda abaixo de R\$ 9o,oo ou meio salário per capita (em abril de 2001) um benefício mensal de R\$ 15,0o, R\$3 30,00, ou R\$ 45,oo por mês, dependendo de a família ter uma, duas ou três crianças freqüentando a escola. No final do ano de 2002, havia cerca de 5,7 milhões de famílias cadastradas neste programa, envolvendo cerca de 10,7 milhões de crianças em 5,545 municípios, quase a totalidade dos 5.561 municípios brasileiros. 0 benefício mensal por família em 2002 era de R\$ 26,70 por mês. O orçamento anual para este programa em 2003 é de R\$ 1.8 bilhão. O Ministério da Educação é o responsável por este programa.

Bolsa Alimentação ou Programa de Renda Mínima vinculada à Saúde, criada em 2001 pelo Decreto 3.934/o1, sob a responsabilidade do Ministério da Saúde, que fornece às gestantes ou mães amamentando, crianças de 6 meses a 6 anos e 11 meses de idade, pertencentes a famílias com renda abaixo de meio salário mínimo per capita, ou para mães portadoras de vírus HIV, um benefício igual a R\$ 15,oo por beneficiário, com um limite de R\$ 45,oo por família por mês. Em novembro de 2002 havia 1.403.010 beneficiários, em 4.110 municípios, representando uma despesa de R\$ 115 milhões. 0 benefício médio por família em 2002 foi de R\$ 21,0o. As famílias beneficiadas devem cumprir determinadas exigências, tais como freqüentar o centro de saúde para vacinação e receber instruções sobre a saúde das crianças. 0 orçamento anual para este programa em 2003 é de R\$36o milhões.

Programa de Auxílio Gás, criado em 2002 pela Lei 10.453/o2, sob a responsabilidade do Ministério de Minas e Energia, para famílias com uma renda per capita abaixo do meio salário mínimo cadastradas no Programa Bolsa Escola ou no Cadastro Único dos Programas Sociais. O benefício é de R\$ 15,oo para cada dois meses para ajudar as famílias pobres a comprar gás, cujo preço aumentou significativamente em 2002.

\footnotetext{
4 Uma boa análise desses programas pode se encontrada no IPEA (Instituto de Pesquisa Econômica Aplicada); SEDH/MJ (Secretaria de Estado dos Direitos Humanos do Ministério da Justiça) e MRE (Ministério das Relações Exteriores) (2002) A Segurança alimentar e nutricional e o direito humano à alimentação no Brasil. Brasília, IPEA.
} 
Em novembro de 2002, havia 8,5 milhões de famílias cadastradas, representando uma despesa de R\$ 502 milhões. 0 orçamento de 2003 para este programa é de R\$ 750 milhões, suficientes apenas para 7,4 milhões de famílias.

Bolsa Renda para famílias em áreas agrícolas atingidas por calamidades públicas e situações de emergência tais como secas e enchentes. O programa é controlado pelo Ministério de Integração Nacional. 0 benefício por família é de R\$ 30,oo mensais enquanto perdurar os efeitos da seca e das enchentes. Em dezembro de 2002, havia 1,6 milhão de famílias beneficiadas pela Bolsa Renda em 959 municípios. Nenhuma provisão foi fixada no orçamento de 2003. Como havia várias áreas em situações de emergência nos primeiros meses de 2003, o Presidente Lula editou uma Medida Provisória para continuar o pagamento do benefício às famílias naquele período. Existem indícios de que o governo pretende transferir os beneficiários deste programa para o Programa de Cartão-Alimentação.

O Ministério da Previdência Social controla o Benefício Social Contínuo, transferindo mensalmente, sob a forma de salário mínimo, o valor de R\$200,oo para os idosos ou para aqueles que precisam de cuidados especiais ou são fisicamente deficientes, pertencentes às famílias com uma renda abaixo de um quarto de salário mínimo per capita e para quem não recebe nenhum outro benefício daquele Ministério ou seguro desemprego. Havia 1,3 milhão de inválidos ou pessoas que necessitam de cuidados especiais e 740.00o idosos protegidos pela Previdência Social em 2002, totalizando uma despesa de R\$ 3,5 bilhões em 2002.

O Ministério da Previdência Social é também responsável pelo controle do Salário Família. Introduzido pela Lei 4.266/1963, modificado várias vezes e mais recentemente pela Emenda Constitucional nr. 20/ 1998, ele proporciona um modesto benefício mensal para cada empregado do setor privado, ou aos autônomos que prestam serviços para empresas, de R\$ 11,26 por filho de até 14 anos de idade, ou mesmo maior, se inválido, desde que o trabalhador receba menos de R\$ 468,47 por mês. Apesar de ser pago primeiramente pelo empregador, o valor é descontado quando o empregador recolher as suas contribuições sociais devidas sobre cada salário. Portanto, de fato, o salário família é financiado pelo Instituto Nacional de Seguridade Social - INSS. Em 2002, o programa representou um total de R\$ 16 milhões.

O Ministério da Previdência Social também transfere mensalmente um salário mínimo permanente aos idosos, viúvas, segurados em licenças de saúde, os que estão se recuperando de acidentes de trabalho ou de doenças, ou segurados que estão em regime de seguridade social especial, desde que tenham trabalhado em atividades rurais familiares. Em 2002 havia 7,3 milhões de dependentes deste programa, totalizando uma despesa de cerca R\$ 15,.3 bilhões. Este Ministério é também responsável pelo regime geral de previdência social para empregados do setor privado e do sistema de previdência social dos servidores públicos. Os dois sistemas diferem em termos de contribuições e em termos de benefícios. Enquanto que empregadores e empregados do setor privado formal contribuem cada um com $8 \%$ sobre o valor do salário ao INSS, e o INSS concede o benefício após 35 anos (homem) ou 30 anos (mulher) de contribuição no montante de $80 \%$ da melhor remuneração obtida desde 1994, multiplicada pelo "fator de previdência social” e limitado ao máximo de $\mathrm{R} \$ 1.561,56$ por mês, os servidores públicos contribuem com $9 \%$ sobre os seus vencimentos e, após 35/30 anos (homem / mulher) de contribuição, com a idade mínima de $65 / 60$ anos, eles podem receber um benefício igual ao valor do último vencimento, sem nenhuma limitação.

Em 2002, havia necessidade de suplementar o Sistema de Previdência Social com R\$ 71,4 bilhões, dos quais R\$ 17 bilhões foram alocados para o Regime Geral de Previdência Social e R\$ 54,4 bilhões para a Previdência Social dos Servidores Públicos. Mas havia muito mais segurados no setor privado. Considerando todos os empregadores e empregados - que também contribuem - no setor privado, em 2001, havia 28,3 milhões contribuintes e 18,7 milhões de contribuintes potenciais no setor informal, totalizando 47 milhões. Considerando todos os servidores públicos das administrações federais, estaduais e capitais estaduais, em 2002 havia 3,7 milhões servidores ativos, 1.6 milhão servidores inativos e 960 mil pensionistas. Considerando a necessidade de corrigir o desequilíbrio crônico e para melhorar a equidade do sistema, é evidente que se torna necessária uma importante reforma previdenciária. 
Entre os programas de transferência de renda, devemos ainda considerar aqueles que estão sob a responsabilidade do Ministério de Trabalho:

Primeiro, o Seguro Desemprego, devido aos trabalhadores que estavam empregados no mercado formal por pelo menos seis meses e perderam os seus empregos nos últimos 36 meses. Eles têm o direito a receber um valor igual ao salário médio recebido durante os últimos três meses de emprego, dentro do limite de um a dois salários mínimos, por um período de três a cinco meses. Em dezembro de 2002, o valor médio do seguro desemprego correspondia a 1,43 salário mínimo. Em 2002, o programa beneficiou 4,7 milhões de trabalhadores, representando um total de R\$ 5,7 bilhões.

Segundo, o Bônus Anual de Um Salário Mínimo a todos os trabalhadores cadastrados por pelo menos cinco anos no Fundo de Participação PIS/PASEP (Programa de Integração Social ou Programa de Formação de Patrimônio do Servidor Público) ou no Cadastro de Trabalhadores (subdivisão do Cadastro Nacional de Informações Sociais). Isto significa que, para ter acesso ao bônus anual, o trabalhador deve ter sido formalmente empregado no setor privado ou no setor público, por pelo menos 30 meses, recebendo menos de dois salários mínimos por mês. No período de julho de 2001 a junho de 2002, havia 5.618.806 beneficiários, representando uma despesa de R\$ R\$ 1,o1 bilhão.

Um exame completo de todas as transferências de renda no Brasil também deve levar em consideração os programas de treinamento financiados pelo Ministério de Trabalho através das Organizações Centrais de Sindicatos de Trabalhadores, como Central Única dos Trabalhadores e Força Sindical, com recursos do Fundo de Amparo ao Trabalhador - FAT. Entretanto, esses não são pagos diretamente às pessoas ou famílias.

Uma outra importante transferência de renda é efetuada através de créditos subsidiados por instituições financeiras oficiais ou através de incentivos fis- cais dados às empresas privadas, ou aos seus proprietários. Entretanto esses não são concedidos diretamente às pessoas e portanto não vamos incluí-los na mesma categoria dos benefícios acima listados.

\section{A Renda Mínima e As Perspectivas da Renda Básica de Cidadania}

Explicarei agora como a discussão sobre uma renda mínima garantida evoluiu no Brasil seguindo a grande necessidade de resolver as sérias desigualdades sociais que caracterizaram a história do nosso país e o desenvolvimento da idéia em várias partes do mundo. No meu livro, Renda de Cidadania. A Saída é Pela Porta. ${ }^{5}$, descrevo em maiores detalhes de como o conceito da renda garantida está relacionado com os valores que devem ser levados em consideração quando fixarmos o objetivo para construir uma sociedade justa e civilizada. Como esta proposta está consistente com os valores universais de humanidade, tais como a busca da verdade, justiça, ética, fraternidade, equidade, solidariedade e liberdade desde o início da História da Humanidade e da História do Brasil.

Portanto, podemos achar aqueles valores de solidariedade e liberdade já presentes na vida diária das comunidades indígenas, de quilombos, as comunidades de afros-descendentes que lutaram contra a escravidão pela liberdade, e nas obras daqueles que lutaram pela independência do Brasil, a abolição da escravidão, os movimentos igualitários dos trabalhadores e intelectuais durante o século 20 e assim por diante. Durante as décadas de 40,50, 6o e 7o, autores como Josué de Castro, Caio Prado Junior, e Celso Furtado foram importantes para mostrar como uma sociedade mais justa poderia e deveria ser construída no Brasil $^{6}$.

Em 1975, Antonio Maria da Silveira foi o primeiro a propor na literatura acadêmica brasileira que uma garantia de renda mínima deveria ser estabelecida através do imposto de renda negativo ${ }^{7}$. Ele argumen-

\footnotetext{
5 SUPLICY, Eduardo Matarazzo Renda de Cidadania. A saída é pela porta. São Paulo. Cortez Editora/Fundação Perseu Abramo, 2002, $2^{0}$.Edição.

6 CASTRO, Josué de. Geografia da fome: o dilema brasileiro: pão ou aço. Rio de Janeiro: Civilização Brasileira, 2001. 318 p. e Geopolítica da fome: ensaio sobre os problemas de alimentação e de população do mundo. Rio de Janeiro: Casa do Estudante do Brasil, 1951.288 p. FURTADO, Celso. Um projeto para o Brasil. 2. ed. Rio de Janeiro: Saga, 1968. 132 p. PRADO JR.,Caio. Formação do Brasil contemporâneo: colônia. 20. ed. São Paulo: Brasiliense, 1987.390 p.

7 SILVEIRA, Antônio Maria da. "Redistribuição da renda". Revista Brasileira de Economia, Rio de Janeiro, v. 29, n. 2, p. 3-15, abr./jun. 1975.
} 
tou que os novos recursos introduzidos na economia todos os anos poderiam ser distribuídos entre os mais pobres. Em 1978, Edmar Lisboa Bacha e Roberto Mangabeira Unger publicaram um livro defendendo uma garantia de renda mínima através do imposto de renda negativo, junto com a reforma agrária, como os principais instrumentos para a construção de uma sociedade mais igualitária ${ }^{8}$. Durante a década de oitenta, o economista Paul Singer e eu debatemos várias vezes com os líderes do Partido dos Trabalhadores (PT - fundado em 10 de fevereiro de 1980) que deveríamos introduzir uma garantia de renda mínima como um objetivo do nosso programa nacional.

Foi em 1991, no meu primeiro ano como o primeiro senador eleito pelo PT, que apresentei um projeto de lei para introdução de uma garantia de renda mínima através do imposto de renda negativo. Cada pessoa com 25 anos de idade ou mais, com uma renda mensal abaixo de US\$150,oo teria o direito a receber uma renda complementar igual a 30\% (ou até 50\%, dependendo da disponibilidade de fundos e da evolução do programa) da diferença entre aquele valor e o seu nível de renda. Em 16 de dezembro de 1991, após quatro horas de debates, o Senado aprovou a proposição com os votos dos senadores de todos os partidos. Apenas quatro dos 81 senadores se abstiveram. Ninguém votou contra. O Senador Fernando Henrique Cardoso, então líder do Partido Social Democrático Brasileiro, argumentou naquele dia que o projeto de lei era uma utopia realista, que se tornou exeqüível pelo Senado, desde que seja implementado gradualmente, de 1995 a 2002, começando com a população de 60 anos ou mais no primeiro ano, de 55 anos ou mais no segundo ano, e assim por diante. 0 projeto de lei foi a Câmara dos Deputados e recebeu um parecer favorável do deputado federal Germano Rigotto (PMDB/RS), mas lá permaneceu, pronto para ser votado, por 11 anos.

A discussão sobre a renda mínima, entretanto, estimulou o interesse na idéia de transferência de renda para famílias pobres com crianças na idade escolar, desde que estejam freqüentando a escola. José Márcio
Camargo ${ }^{9}$, Cristóvam Buarque, e José Roberto Magalhães Teixeira fizeram contribuições relevantes à matéria, os últimos sendo responsáveis, respectivamente como governador do Distrito Federal e prefeito, em 1995. Em ambos os casos, famílias com uma renda familiar abaixo do meio salário mínimo per capita tiveram o direito a receber uma renda complementar, desde que a família tenha crianças freqüentando a escola. Enquanto em Campinas o benefício era definido como uma quantia necessária para alcançar meio salário mínimo per capita para aquela renda familiar, no Distrito Federal o benefício foi de exatamente um salário mínimo, independentemente do tamanho da família. Desde então, municípios como Ribeirão Preto, São José dos Campos, Belém, Belo Horizonte, Mundo Novo, Blumenau, Jundiaí, Campinas, Piracicaba, Caxias do Sul, São Paulo, e muitos outros instituíram programas com variações nos benefícios, com base no mesmo princípio.

Uma vez que essas experiências mostraram resultados positivos, novos projetos de lei foram apresentados em 1995 e 1996, na Câmara dos Deputados e no Senado, como os projetos de lei de Nélson Marchezan (PSDB), Pedro Wilson (PT), Chico Vigilante (PT), José Roberto Arruda (PSDB), Ney Suassuna (PMDB), e Renan Calheiros (PMDB), propondo programas de renda mínima vinculada à educação, ou Programas Bolsa Escola. Em 1996, quando Philippe Van Parijs veio ao Brasil, acompanhei-o numa reunião com o Presidente Cardoso. Naquela ocasião, Van Parijs afirmou que era um passo positivo começar conceder uma renda garantida a famílias vinculada às oportunidades educacionais. Era uma boa forma de vincular aquela renda ao investimento em capital humano. Aqueles movimentos levaram à aprovação pelo Congresso Nacional, primeiramente da Lei 9.533/1997 e depois da Lei 10.219/2002, que hoje regula a Renda Mínima vinculada à Educação ou Programa Bolsa Escola já descrito acima.

Nos anos recentes, os vários programas de transferência de renda tais como a Bolsa Escola, Bolsa Alimentação, e Bolsa Renda passaram a ser pagos atra-

8 BACHA, Edmar Lisboa; UNGER, Roberto Mangabeira. Participação, salário e voto: um projeto de democracia para o Brasil. Rio de Janeiro. Paz e Terra, 1978. 75 p.

9 CAMARGO, José Márcio. Os miseráveis. Folha de São Paulo, São Paulo, 28 mar. 1993. Caderno Finanças, Seção Opinião econômica, p. 2; e Pobreza e garantia de renda mínima. Folha de São Paulo, São Paulo, 26 dez. 1991. Caderno Dinheiro, Seção Opinião econômica, p. 2. 
vés de cartões magnéticos, distribuídos pela Caixa Econômica Federal, os cartões geralmente entregues às mães de cada família. Em junho de 2001, o Presidente Fernando Henrique Cardoso anunciou que um Cadastro Único dos Programas Sociais, assim como um único "Cartão do Cidadão" seriam instituídos para abranger gradualmente todos os programas de renda diretos existentes nos vários órgãos federais.

É importante considerar que em vários municípios e estados, inúmeros programas de renda mínima, bolsa-escola, e muitos outros foram instituídos independentemente dos do Governo Federal. Na maioria dos casos, os programas municipais ou estaduais proporcionam benefícios mais generosos que os estabelecidos pela União. Em alguns casos, o município ou o estado pode usar os recursos federais para o programa como foi definido pela lei federal e complementálos com lei estadual ou municipal mais generosa. É o caso de São Paulo, por exemplo, onde a prefeita Marta Suplicy (PT) implantou o Programa de Garantia de Renda Familiar Mínima Municipal logo no início da sua gestão em 2001.

Hoje, em São Paulo, a maior cidade do Brasil, com 10,4 milhões de habitantes - existem 194.ooo famílias cadastradas no Programa de Garantia de Renda Familiar Mínima Municipal. Famílias com uma renda mensal abaixo de meio salário mínimo per capita o salário mínimo hoje é de R\$ 200,oo por mês - com crianças de seis a quinze anos de idade - desde que freqüentem a escola - têm direito a receber uma renda complementar que corresponde a dois terços da diferença entre o número de membros da família vezes metade do salário mínimo e a renda da família. 0 programa está sendo implementado gradualmente para incluir cerca de 300.0oo famílias que atendem àqueles requisitos em São Paulo. 0 critério era para começar primeiro com o cadastramento das famílias pobres nos distritos onde as taxas de desemprego e de violência criminal eram mais altas e renda per capita mais baixa. Após quase dois anos de experiência, os resultados positivos naqueles distritos onde o programa foi implementado primeiramente, comparados com a situação anterior, se tornaram evidentes. Havia maior presença de crianças nas escolas, crescimento na atividade econômica porque as famílias começaram a gastar a sua renda extra nos distritos onde moram, mais oportunidades econômicas e redução de incidências de violência criminal. Existem outros programas sociais administrados pelo município de São Paulo: a Bolsa-Trabalho, que concede uma renda modesta de R\$ 146,oo aos jovens de 16 a 20 anos por um período de treinamento de seis meses; a Operação Trabalho que concede $\mathrm{R}$ \$15, oo para um período de treinamento de 3 a 9 meses àqueles que perderam os seus empregos e estão na faixa de idade de 21 a 39 anos, e Começar de Novo, um programa de treinamento para os desempregados com 40 anos de idade ou mais, que concede R\$189,oo mensalmente por um período de seis meses. Considerando a existência de 589.000 famílias vivendo com menos de 1.47 salário mínimo por mês, considerado como uma linha de pobreza em 2000, incluindo aqueles que não têm filhos até 16 anos de idade, 266.ooo famílias já foram beneficiadas pelos 4 programas listados acima.

Em dezembro de 2002, logo antes da inauguração do governo Lula, a sua equipe de transição, coordenada pelo atual Ministro da Fazenda Antonio Palocci preparou um relatório recomendando a coordenação e a unificação de todos os programas de transferência de renda, incluindo o que estava para ser criado para ser vinculado ao Programa Fome Zero. Essa coordenação deveria também incluir a integração dos programas da União, do Estado e dos Municípios, como os existentes em São Paulo, descritos acima. De acordo com esse relatório, os programas devem ter os mesmos critérios com relação ao nível da renda familiar per capita que permite a participação da família, eles devem ser financiados por um fundo unificado, e o Cadastro Único dos Programas Sociais deve ser aperfeiçoado e consolidado através de uma nova Lei.

Existe um risco de o "cartão do cidadão", ou o "cartão-alimentação", hoje sendo anunciado pela administração do Lula ser identificado para sempre como um símbolo de não-cidadania, de exclusão, como previsto pelo deputado federal e economista Antonio Delfim Netto na Folha de S. Paulo (20 de maio de 2002). Após considerar exaustivamente a melhor forma de garantir uma renda para todos, após interagir bastante com todos os membros da BIEN, Basic Income European Network, e mais recentemente com a USBIG, United States Basic Income Guarantee Network, após ter lido as contribuições de Philippe Van Parijs, Guy Standing, James Tobin, James Edward Meade, Tony Atkinson, Claus Offe, e muitos outros, e após ter acompanhado 
de perto as inúmeras experiências realizadas fora do Brasil e em muitos outros países, fiquei convencido de que a melhor forma e o melhor plano para evitar o risco é uma renda de cidadania básica incondicional paga igualmente a todos, independentemente da origem, raça, sexo, idade, estado civil ou condição sócioeconômica ${ }^{10}$.

Consistentemente, em dezembro de 2001, apresentei no Senado Federal do Brasil um novo projeto de lei introduzindo uma renda básica de cidadania a partir de 2005 a todos os brasileiros residentes e mesmo estrangeiros residentes no Brasil por cinco anos ou mais, que será paga em prestações iguais, anualmente, e se possível, mensalmente, não importando a sua situação sócio-econômica. Mesmo os ricos receberão a renda básica de cidadania? Sim. Mas, é claro que eles vão contribuir proporcionalmente mais para eles mesmos e todos também receberão. Quais são as grandes vantagens deste procedimento?

Primeiro, diminuiremos substancialmente a burocracia envolvida de ter que perguntar a cada um, para a finalidade de receber uma renda básica, de quanto cada um está ganhando no mercado formal e no mercado informal de trabalho. Segundo, se tivermos um sistema simples para explicar que todos têm o direito a receber uma renda básica, independentemente de sua posição ou atributos, é provável que a abrangência do programa entre os pobres seja maior do que se tivermos que estabelecer condições que, por exemplo, existem nos atuais programas de transferência de renda. Terceiro, eliminaremos qualquer estigma ou sentimento de vergonha de qualquer pessoa que precisaria dizer que ela ganha apenas uma certa quantia de dinheiro ou nada, e que, por causa dessa situação, ela merece essa renda complementar. Quarto, com os instrumentos tecnológicos da era de informática e do uso de cartões magnéticos, é bastante provável que os custos para a concessão de renda básica para todos na sociedade sejam menores do que se precisássemos nos preocupar com controles administrativos dos meios para teste das exi- gências. Quinto, e mais importante, do ponto de vista da dignidade e liberdade de cada pessoa, não há dúvida de que ela se sentirá muito melhor sabendo de que nos próximos 12 meses, e ano após ano desde então, ela terá o direito a receber uma renda modesta, suficiente para atender as suas necessidades básicas, que aumentará com o progresso da economia do país nos anos seguintes.

É importante entender que a renda básica de cidadania é uma reforma radical na sociedade porque ela transforma a relação existente entre uma pessoa e qualquer empregador em potencial. Se ela tem uma renda garantida, ela pode responder sim ou não ao empregador diante de uma oferta de trabalho que poderia eventualmente ser ofensiva, depreciativa, humilhante, ou que poderia colocar a sua vida em risco.

Duas perguntas freqüentes são sempre formuladas quando a idéia da renda mínima ou básica é proposta. Por que não instituir programas que criam empregos? Haverá um incentivo para ociosidade?

Primeiro, a criação de uma renda básica é bastante consistente com a criação de um grande estímulo para o crescimento da economia numa melhor direção para expansão da oferta de bens e serviços que as pessoas mais precisam, incluindo alimentação.Uma pesquisa realizada entre os beneficiários do programa de renda mínima em São Paulo mostrou que 85\% de sua renda adicional recebida do programa eram gastos no mesmo distrito onde moram e que 70\% de suas despesas eram gastos em alimentos.

Segundo, porque devemos nos preocupar tanto com aqueles que têm vocação para serem preguiçosos?. Como Bertrand Russell mencionou, no seu livro de 1918 Estrada para Liberdade, eles são poucos ${ }^{11}$. Existem muitas atividades (como nutrição de bebês e cuidados com crianças e com idosos) que são muito importantes e nem sempre pagas pelo mercado. Existem também trabalhos que não são reconhecidos pelo mercado da mesma forma como eles são produzidos, tais como as obras de A. Modigliani e Vincent Van Gogh. Mas ainda mais importante, a Constituição Bra-

10 VAN PARIJS, Philippe (2001). What's Wrong with a Free Lunch? Prefácio por Robert M. Solow. New Democracy Forum Series. Boston, Beacon Press; (1995). Real freedom for all: what (if anything) can justify capitalism? Oxford, Oxford University Press; (1994). "Au delà de la solidarité. Los fondements éthiques de l'Etat-providence et de son dépassement”. Futuribles, Revista Mensal, nº 184, fevereiro, pp 5 - 29; (ed.) (1992). Arguing for basic income: ethical foundations for a radical reform. London, Verso; (1991). Qu'est-ce qu'une société juste? Introduction à la pratique de la philosophie politique, Paris, Le Seuil ("La Couleur des idées").

11 RUSSELL, B. Proposed Roads to Freedom. Socialism, Anarchism and Syndicalism. New York: Cornwall Press, 1918. 
sileira, e as da maioria das nações, reconhecem o direito da propriedade privada. Isto significa o direito dos proprietários do capital a receber aluguéis, juros e lucros, mesmo sem trabalhar. Mas em geral eles trabalham e mandam os seus filhos para escola. Porque eles querem progredir. Se admitirmos que os ricos recebam uma renda mesmo sem trabalhar, porque não admitirmos que todos, ricos e pobres, tenham uma renda básica?

Existe algum lugar no mundo onde uma renda igual é paga a todos como direito do cidadão de participar da riqueza do estado? Sim. No Estado de Alasca, nos EUA, desde 1980, com muitos resultados positivos. Em 1976, o governador Jay Hammond propôs a todos os habitantes de Alasca que eles separassem $50 \%$ dos royalties da exploração do petróleo e outros recursos naturais para constituir um fundo que pertenceria a todos os habitantes do Alasca. A proposta foi aceita pela Assembléia Estadual e por um referendo popular, com um resultado positivo de dois por um em favor da proposta. Na época o Alasca tinha 300.000 habitantes. A receita do Fundo Permanente do Alasca começou a ser investida em títulos dos Estados Unidos, do Alasca, em ações dos EUA e do mercado internacional, além de imóveis. O valor do patrimônio líquido do fundo aumentou de US \$ 1 bilhão, em 1990, para US \$ 25 bilhões em 2002.

O sistema de dividendos iguais pagos anualmente a todos os residentes do Alasca, por um ano ou mais, produziu crescimento econômico mais estável e fez do Alasca o estado mais igualitário de todos os 50 estados norte-americanos. Nos últimos 10 anos, Alasca distribuiu 6\% do seu Produto Interno Bruto igualmente a todos os seus habitantes, que eram cerca de 626.00o em 2002. No ano passado o dividendo era de US $\$ 1.550$,oo por pessoa. Como resultado ${ }^{12}$, enquanto que nos EUA a renda média das $20 \%$ famílias mais ricas cresceu $26 \%$, a renda média das $20 \%$ famílias mais pobres cresceu $12 \%$. No Alasca, durante o mes- mo período de 10 anos, as $20 \%$ famílias mais ricas tiveram um crescimento na sua renda média de $7 \%$, enquanto que as $20 \%$ famílias mais pobres tiveram um crescimento na sua renda média de $28 \%$. Não há dúvida de que esta é a maneira correta em direção a uma sociedade mais justa, melhorando o coeficiente de desigualdade do Gini. É necessária apenas uma vontade política para realizá-la.

Gostaria de concluir com algumas boas notícias para aqueles que estão convencidos como eu de como uma renda básica poderá ajudar a construir sociedades melhores. Em dezembro de 2002, o Senado brasileiro, com os votos de todos os partidos, votou unanimemente em favor do projeto de lei para introduzir gradualmente, a partir de 2005, uma renda básica de cidadania, paga igualmente a todos os brasileiros, e mesmo aos estrangeiros residentes no Brasil por 5 anos ou mais, começando por aqueles que mais precisam, com critérios a serem estabelecidos pela Câmara dos Deputados. Envidarei os meus melhores esforços para vê-lo aprovado num futuro próximo, de forma que o Presidente Luiz Inácio Lula da Silva possa assinar a sua transformação em lei antes do Congresso Internacional do BIEN - Basic Income European Network em setembro de 2004.

É importante notar que o Plano de Governo do Lula, aprovado pelo Congresso Nacional do PT em 2001, enfatizou que a renda mínima e outras formas de programas de transferência de renda deveriam se vistas como passos em direção à renda básica de cidadania. A decisão foi reforçada recentemente pela Resolução de Março de 2003 do Diretório Nacional do PT (uma resolução aprovada após o meu retorno da Inglaterra e Nova York). Esta resolução recente também menciona que as reformas da legislação trabalhista, da previdência e tributária, que serão apresentadas brevemente ao Congresso Nacional, devem levar em consideração a criação da renda básica de cidadania a partir de 2005 .

12 GOLDSMITH, Scott. “The Alaska Permanent Fund Dividend: An Experiment in Wealth Distribution" $9^{\text {th }}$ International Congress BIEN (Basic Income European Network). Geneva, September $12^{\text {th }}-14^{\text {th }}$. 